It is hoped next year to visit cuttings to be made near Pinner and Bushey, when interesting sections in the Basement Bed of the London Clay and the Reading Beds will probably be exposed.

\title{
VISIT TO THE MINERAL COLLECTION AT THE IMPERIAL INTERNATIONAL EXHIBITION, SHEPHERD'S BUSH.
}

SATURDAT, SEPTEMBER 4TH, I 909.

Directors: The late Prof. H. Bauerman, A.M.I.C.E., A.R.S.M., F.G.S., AND H. T. Burls, F.G.S., M.I.M.E.

The Cornish Committee's excellent exhibit of minerals was inspected and was explained by Mr. E. IV. Newton.

The minerals in the official collection are selected from the Collections of the School of Mines, Camborne, and the Royal Geological Society of Cornwall, Penzance, and include practically every species found in the county.

It is supplemented by collections from the following exhibitors: The School of Mines, Redruth, who exhibit a case of metallic minerals of especial interest; Mr. James Wickett, Redruth, who sends perhaps the most interesting collection in this section, the tin specimens being exceptionally fine, and showing varieties from many localities now unobtainable; this also applies to his fine and complete series of copper arseniates, many of which were found in the early part of the last century when the Cornish mines were so rich in copper. A fine case of pitchblende and other uranium minerals and products is exhibited by the British Metalliferous Mining Company from their mines at Grampound; and a case of minerals by Mr. E. IV. Newton.

The combined exhibits in this section form, no doubt, the finest and most complete collection of Cornish minerals ever on exhibition, and prove conclusively that Cornwall produces practically every mineral of commercial importance, from gold on the one hand, to uranium (and incidentally radium) on the other; and it is probably the most highly mineralized district in the world.

Cases illustrating the preparation of china clay and china stone in their various stages, the different varieties of Cornish granite and their uses, and the machinery used in Cornish mining were examined and explained.

Much interest was also shown in Mr. Burls' collection of auriferous rocks and specimens of gold obtained from Ogofan, South Wales. 